\title{
Low levels of inflammation and the absence of subclinical atherosclerosis in rheumatoid arthritis
}

\author{
SALVATORE SANTO SIGNORELLI ${ }^{1}$, SAVERIO CANDIDO ${ }^{2}$, ROSSELLA SALEMI ${ }^{2}$, \\ VALERIO FIORE $^{1}$, MARCO MANGIAFICO $^{1}$ and MASSIMO LIBRA ${ }^{2}$
}

\author{
${ }^{1}$ Department of Clinical and Experimental Medicine, Medical Angiology Unit, Garibaldi Hospital, \\ University of Catania, Catania I-95123; ${ }^{2}$ Department of Biomedical and Biotechnological Sciences, \\ Section of General \& Clinical Pathology and Oncology, University of Catania, Catania I-95123, Italy
}

Received April 11, 2015; Accepted September 25, 2015

DOI: $10.3892 / \mathrm{mmr} .2016 .4962$

\begin{abstract}
Rheumatoid arthritis (RA) is a chronic autoimmune inflammatory disease. Patients with RA have an increased risk for the development of cardiovascular diseases, however, the pathophysiological mechanisms of arterial complications in RA remain to be fully elucidated. Understanding the early markers of vascular damage may aid in preventing cardiovascular complications in patients with RA. The current study investigated this by recruiting 30 patients with RA and 30 healthy subjects. Intima-media thickness (IMT) was used to detect the presence of atherosclerotic disease and was measured in the carotid and femoral arteries. Tumor necrosis factor $\alpha$, interleukin-6 (IL-6), IL-8, IL-10 and matrix metalloproteinase- 2 were measured as markers of inflammation. An IMT $\geq 0.9 \mathrm{~mm}$ was observed in $7 / 30$ patients with RA, however, no significant differences between patients with RA and the controls were observed in the inflammatory markers analyzed. Of note, these results indicated that the appropriate management of RA may have affected the inflammatory status of these patients and consequently may have impacted upon subclinical atherosclerosis.
\end{abstract}

\section{Introduction}

Rheumatoid arthritis (RA) is a chronic inflammatory disease that affects $\sim 1 \%$ of the general population, and is associated with a high rate of morbidity or mortality due to cardiovascular diseases (CVDs) (1-7). Mortality associated with CVD is $35-50 \%$ higher in patients with RA compared with the general population (4). Previous studies have focused on markers

Correspondence to: Professor Salvatore Santo Signorelli, Department of Clinical and Experimental Medicine, Medical Angiology Unit, Garibaldi Hospital, University of Catania, Piazza Santa Maria di Gesù, 7, Catania I-95123, Italy

E-mail: ssignore@unict.it

Key words: biomarkers, inflammation, atherosclerosis, rheumatoid arthritis of subclinical atherosclerosis, however, the results appear controversial (8-11). Furthermore, the association between RA and CVD complications was investigated by flow mediated vasodilation, pulse wave velocity and the measurement of intima-media thickness (IMT) using ultrasound (US) (12-16). Understanding the early markers of vascular damage may prevent cardiovascular complications in patients with RA. Therefore, the current study analyzed the plasma levels of known inflammatory biomarkers in addition to measuring the IMT of the carotid and femoral arteries.

\section{Patients and methods}

A total of 30 patients who were diagnosed with RA according to the American Rheumatology Association guidelines (16) and treated at the Rheumatology Unit of the Garibaldi Hospital (Catania, Italy) were recruited for the current study (Table I). All patients were treated with disease modifying anti-rheumatic drugs (DMARDs) or with tumor necrosis factor $\alpha$ (TNF- $\alpha$ ) blockade drugs following failure with DMARDs. Patients included in the present study were defined as "clinically stable patients", with a low pain grade, articular motility and no ankylosing spondylitis. A total of 30 voluntary healthy subjects were enrolled as controls. The present study was approved by the Ethics Committee of Garibaldi Hospital (Catania, Italy) and all patients and volunteers provided informed consent to participate in the study.

IMT measurement. US examination of the carotid and the femoral arteries was conducted in all study participants. The IMT was measured in the common carotid arteries, $1 \mathrm{~cm}$ below the arterial bifurcation, and in the origin of the common femoral arteries of the lower limbs. The results of the US examinations were stored prior to an additional evaluation, conducted blind by a different physician. An IMT value of $\geq 0.9 \mathrm{~mm}$ was considered as a marker for cardiovascular risk and for atherosclerotic plaque formation in the carotid and/or in the common femoral arteries. A MyLab $^{\text {TM }} 70$ XVision US system, (Esaote SpA, Genoa, Italy), equipped with a $7 \mathrm{mHz}$ linear probe (Esaote $\mathrm{SpA}$ ), was used to perform the US measurements. 
Table I. Clinical characteristics of patients with rheumatoid arthritis.

\begin{tabular}{lr}
\hline Clinical characteristic & Value \\
\hline Age (years) & $55.6 \pm 5.3$ \\
Disease duration (years) & $6.5 \pm 2.1$ \\
Gender & 8 \\
Male (n) & 23 \\
Female (n) & 7 \\
Dyslipidemia & 23 \\
Yes (n) & 12 \\
No (n) & 18 \\
Arterial hypertension & 7 \\
Yes (n) & 23 \\
No (n) & \\
Intima-media thickness (carotid artery) & \\
$\geq 0.9$ mm (n) & \\
$<0.9$ mm (n) & \\
\hline
\end{tabular}

${ }^{a}$ Mean \pm standard deviation; $n$, number of patients.

Table II. Median concentrations of inflammatory biomarkers in patients with RA and controls.

\begin{tabular}{lccc}
\hline Biomarker & Patients with RA, $\mathrm{n}=30$ & Controls, $\mathrm{n}=30$ & P-value \\
\hline TNF- $\alpha(\mathrm{pg} / \mathrm{ml})$ & $0.45(0.35-1)$ & $0.37(0.26-0.68)$ & $\mathrm{NS}$ \\
IL-6 $(\mathrm{pg} / \mathrm{ml})$ & $0.85(0.59-1.62)$ & $0.88(0.55-1.51)$ & $\mathrm{NS}$ \\
MMP-2 $(\mathrm{ng} / \mathrm{ml})$ & $275.00(244.21-296.17)$ & $236.36(219.34-284.62)$ & $\mathrm{NS}$ \\
IL-10 $(\mathrm{pg} / \mathrm{ml})$ & $0.78(0.78-0.78)$ & $0.80(0.78-0.91)$ & $\mathrm{NS}$ \\
IL-8 $(\mathrm{pg} / \mathrm{ml})$ & $14.22(10.32-16.6)$ & $12.67(10.02-21.36)$ & $\mathrm{NS}$ \\
\hline
\end{tabular}

Parentheses contain the 25 th and 75 th percentile range values. P-values were calculated using the Mann-Whitney U test. RA, rheumatoid arthritis; TNF- $\alpha$, tumor necrosis factor $\alpha$; IL, interleukin; MMP-2, matrix metalloproteinase-2; NS, non significant.

Inflammatory markers. Measurement of the inflammatory markers was conducted at the Department of Biomedical and Biotechnological Sciences of the University of Catania (Catania, Italy). Blood was collected from each patient and the healthy controls, and was drawn into pyrogen-free blood collection tubes (BD Vacutainer Plus plastic citrate tube and BD Vacutainer rapid serum tube; Becton Dickinson, Franklin Lakes, NJ, USA), to obtain plasma and serum. Citrated platelet-poor plasma was produced using two centrifuge steps: $5 \mathrm{~min}$ at $1,000 \mathrm{x} \mathrm{g}$ and $10 \mathrm{~min}$ at $2,000 \mathrm{xg}$ at room temperature. Multiple aliquots of serum and plasma were stored at $-80^{\circ} \mathrm{C}$ prior to analysis. IL-6 (cat. no. HS600B), IL-8 (cat. no. HS800), IL-10 (cat. no. HS100C), TNF- $\alpha$ (cat. no. DTA00C) and MMP-2 (cat. no. MMP200) were measured by enzyme-linked immunosorbent assays (R\&D Systems Europe, Ltd., Abingdon, UK). All assay procedures were conducted according to the manufacturer's instructions. Control specimens were analyzed simultaneously on each plate for each marker.

Statistical analysis. Quantitative variables are presented as the median with the 25 th and 75 th percentiles. The IMT mean values were compared by the Mann-Whitney U test. To evaluate the correlation of IMT with age and disease duration, Spearman's test was used. Statistical analysis was performed using the The R Project for Statistical Computing (version 3.0.3; https://www.r-project.org/). P $<0.05$ was considered to indicate a statistically significant difference.

\section{Results}

IMT measurement. A carotid IMT value of $\geq 0.9 \mathrm{~mm}$ was observed in $7 / 30$ patients with RA (23\%). However, no patients exhibited an IMT of $\geq 0.9 \mathrm{~mm}$ in the femoral arteries. IMT was correlated with age $(\mathrm{R}=0.6, \mathrm{P}<0.001)$ and duration of the disease $(\mathrm{R}=0.4, \mathrm{P}<0.005)$ in the $\mathrm{RA}$ group (data not shown).

Inflammatory biomarkers. Table II presents the mean values of TNF- $\alpha$, IL-6, IL-8, IL-10 and MMP-2, analyzed in patients with RA compared with those in the control group. No significant differences between patients with RA and the controls were observed for all the markers analyzed $(\mathrm{P}>0.05$; Table II). 


\section{Discussion}

CVD is a common complication for patients with RA, with patient outcomes affected by the high morbidity and mortality associated with CVDs. The chronic low-level inflammation observed in patients with RA may explain the rate of CVD (17-19). High levels of anti-cyclic citrullinated peptide antibodies have been observed in patients with RA and may contribute to the development of CVD (20). High plasma levels of pro-inflammatory cytokines including IL-1, IL-6 and TNF- $\alpha$ in addition to elevation of C-reactive protein (CRP), are observed in patients with RA, and are suggested to serve a crucial role in the association between RA and atherosclerosis (21). It has been demonstrated that high plasma levels of CRP are associated with increased cardiovascular risk, however, to date the potential and additive effects mediated by this protein on the conventional risk factors for CVD (i.e. obesity, hypertension, hyperlipidemia) remain to be fully understood (22). A prospective analysis demonstrated that a positive test for rheumatic factors, active articular damage and subcutaneous nodules, in addition to further clinical indicators, were useful in the assessment of cardiovascular risk, and their combination with certain conventional factors (such as age and gender) improved the risk prediction for CVDs (23). A genetic study demonstrated the capability of an IL-6 polymorphism to increase IL-6 levels (24) with this polymorphism associated with higher levels of acute phase reactive proteins (such as CRP and fibrinogen) and, consequently, with an increased risk of CVDs. The association between polymorphisms and subclinical atherosclerosis in patients with RA was demonstrated in a previous study in which the TT genotype of the ZC3HC1 rs11556924 polymorphism was observed to be associated with greater IMT values (25). However, the evidence is conflicting, with a study investigating Toclizumab, an anti-TNF- $\alpha$ drug, observing an immunological profile similar to the IL- 6 receptor polymorphism, indicating that the association between inflammation and conventional risk factors for CVDs is unclear (26).

The early and aggressive treatment with anti-inflammatory drugs is suggested by treatment guidelines for patients with RA, and aims to reduce clinical symptoms (pain, functional limitations, regional inflammation, ankylosis and ankylosing spondylitis) and additionally, to reduce the risk and occurrence of CVD (26). Treatment with DMARDs has been demonstrated to have clinical and preventive beneficial effects. The combination of methotrexate, hydroxychloroquine and sulfalazine is recommended in patients with high and/or moderate disease, and in addition, these drugs were able to influence the CVDs risk in patients with RA $(27,28)$. Therapy with anti-TNF- $\alpha$ drugs has been suggested for patients with RA that failed to exhibit improvements using DMARDs (26). The aim of current treatment for RA is to reduce clinical symptoms of RA and CVD risk (29-32). However, arterial remodeling, as the first step in the atherosclerotic process, leading progressively to atherosclerotic plaque generation, has been demonstrated in patients with RA (33). A close association between carotid arterial remodeling and the progression of arterial damage has been previously demonstrated in patients with RA with a long disease duration (34). However, additional studies have indicated maladaptive outward remodeling of the carotid artery alone in patients with RA (35). Previous studies have not indicated any differences between patients with RA and healthy subjects with regards to the carotid IMT $(33,36,37)$. The IMT is considered as an effective and useful marker to indicate the arterial process or to suspect large arterial involvement (13-15). In addition, the IMT of the carotid artery has been suggested to explain the risk and the morbidity rate for CVDs in the patients with RA who are without additional risk factors, including diabetes, dyslipidemia and hypertension (30).

The current study focused on the arterial remodeling process of the carotid and femoral arteries as indicated by the IMT in patients with RA diagnosed with a moderate disease duration $(6.5 \pm 2.1$ years $)$, in addition to measuring the plasma levels of inflammatory biomarkers. The results of the current study demonstrated that only a small proportion of the patients with RA (7/30) exhibited abnormal carotid IMT values ( $\geq 0.9 \mathrm{~mm}$ ), with none of the patients $\geq 0.9 \mathrm{~mm}$ in the femoral arteries. Median plasma levels of the inflammatory markers in the patients with RA were not significantly different when compared with those measured in the controls subjects. Overall, these results suggest that appropriate management of RA reduces the inflammatory status of patients and consequently may affect subclinical atherosclerosis. Of note, all enrolled patients were treated with standard therapy including DMARDs and anti-TNF- $\alpha$. The long-term treatment with these compounds in patients with RA has demonstrated clinical efficacy, further supported by the US examination of the carotid and femoral arteries, as only a small proportion of patients with RA exhibited arterial remodeling.

\section{References}

1. Lawrence RC, Helmick CG, Arnett FC, Deyo RA, Felson DT, Giannini EH, Heyse SP, Hirsch R, Hochberg MC, Hunder GG, et al: Estimates of the prevalence of arthritis and selected musculoskeletal disorders in the United States. Arthritis Rheum 41: 778-799, 1998.

2. Dadoun S, Zeboulon-Ktorza N, Combescure C, Elhai M, Rozenberg S, Gossec L and Fautrel B. Mortality in rheumatoid arthritis over the last fifty years: Systematic review and meta-analysis. Joint Bone Spine 80: 29-33, 2013.

3. Aviña-Zubieta JA, Choi HK, Sadatsafavi M, Etminan M, Esdaile JM and Lacaille D: Risk of cardiovascular mortality in patients with rheumatoid arthritis: A meta-analysis of observational studies. Arthritis Rheum 59: 1690-1697, 2008.

4. Avina-Zubieta JA, Thomas J, Sadatsafavi M, Lehman AJ and Lacaille D: Risk of incident cardiovascular events in patients with rheumatoid arthritis: A meta-analysis of observational studies. Ann Rheum Dis 71: 1524-1529, 2012.

5. Goodson NL, Wiles NJ, Lunt M, Barrett EM, Silman AJ and Symmons DP: Mortality in early inflammatory polyarthritis: Cardiovascular mortality is increased in seropositive patients. Arthritis Rheum 46: 2010-2019, 2002.

6. Young A, Koduri G, Batley M, Kulinskava E, Gough A, Norton S and Dixey J. Early Rheumatoid Arthritis Study (ERAS) group. Mortality in rheumatoid arthritis. Increased in the early course of disease, in ischaemic heart disease and in pulmonary fibrosis. Rheumatology (Oxford) 46: 350-357, 2007.

7. Kremers HM, Crowson CS, Therneau TM, Roger VL and Gabriel SA. High ten-year risk of cardiovascular disease in newly diagnosed rheumatoid arthritis patients: A population-based cohort study. Arthritis Rheum 58: 2268-2274, 2008.

8. Maradit-Kremers H, Nicola PJ, Crowson CS, Ballman KW and Gabriel SE: Cardiovascular death in rheumatoid arthritis: A population-based study. Arthritis Rheum 52: 722-732, 2005.

9. Evans MR, Escalante A, Battafarano DF, Freeman GL, O'Leary DH and del Rincon I: Carotid atherosclerosis predicts incident acute coronary syndromes in rheumatoid arthritis. Arthritis Rheum 63: 1211-1220, 2011. 
10. Van Doornum S, McColl G and Wicks IP: Accelerated atherosclerosis: An extraarticular feature of rheumatoid arthritis? Arthritis Rheum 46: 862-873, 2002.

11. Shoenfeld Y, Gerli R, Doria A, Matsuura E, Cerinic MM, Ronda N, Jara LJ, Abu-Shakra M, Meroni PL and Sherer Y: Accelerated atherosclerosis in autoimmune rheumatic diseases. Circulation 112: 3337-3347, 2005.

12. Kerekes G, Soltész P, Nurmohamed MT, Gonzalez-Gay MA, Turiel M, Végh E, Shoenfeld Y, McInnes I and Szekanecz Z: Validated methods for assessment of subclinical atherosclerosis in rheumatology. Nat Rev Rheumatol 8: 224-234, 2012.

13. Gonzalez-Juanatey C, Llorca J, Martin J and Gonzalez-Gay MA: Carotid intima-media thickness predicts the development of cardiovascular events in patients with rheumatoid arthritis. Semin Arthritis Rheum 38: 366-371, 2009.

14. Corrales A, González-Juanatey C, Peiró ME, Blanco R, Llorca J and González-Gay MA: Carotid ultrasound is useful for the cardiovascular risk stratification of patients with rheumatoid arthritis: Results of a population-based study. Ann Rheum Dis 73: 722-727, 2014

15. Scarno A, Perrotta FM, Cardini F, Carboni A, Annibali G, Lubrano E and Spadaro A: Beyond the joint: Subclinical atherosclerosis in rheumatoid arthritis. World J Orthop 5: 328-335, 2014.

16. Hochberg MC, Chang RW, Dwosh I, Lindsey S, Pincus T and Wolfe F: The American College of Rheumatology 1991 revised criteria for the classification of global functional status in rheumatoid arthritis. Arthritis Rheum 35: 498-502, 1992.

17. El-Barbary AM, Hussein MS, Rageh EM, Hamouda HE, Wagih AA and Ismail RG: Effect of atorvastatin on inflammation and modification of vascular risk factors in rheumatoid arthritis. J Rheumatol 38: 229-235, 2011.

18. Kerola AM, Kauppi MJ, Kerola T and Nieminen TV: How early in the course of rheumatoid arthritis does the excess cardiovascular risk appear? Ann Rheum Dis 71: 1606-1615, 2012

19. Symmons DP and Gabriel SE: Epidemiology of CVD in rheumatic disease, with a focus on RA and SLE. Nat Rev Rheumatol 7: 399-408, 2011.

20. Barbarrroia N,Perez-Sanchez C,Ruiz-Limon P,Castro-Villegas C, Aguirre MA, Carrettero R, Segui P, Jimenez-Gomez Y, Sanna M, Rodriguez-Ariza A et al: Anticyclic citrullinated protein antibodies are implicated in the development of cardiovascular disease in rheumatoid arthritis. Arterioscler Thromb Vasc Biol 34: 2706-2716, 2014.

21. Emerging Risk Factors Collaboration, Kaptoge $\mathrm{S}$ Di Angelantonio E, Pennells L, Wood AM, White IR, Gao P, Walker M, Thompson A, Sarwar N, et al: C-reactive protein, fibrinogen, and cardiovascular disease prediction. N Engl J Med 367: 1310-1320, 2012

22. Grad E and Danenberg HD: C-reactive protein and atherothrombosis: Cause or effect? Blood Rev 27: 23-29, 2013.

23. Solomon DH, Kremer J, Curtis JR, Hochberg MC, Reed G, Tsao P, Farkouh ME, Setoguchi S and Greenberg JD: Explaining the cardiovascular risk associated with rheumatoid arthritis: Traditional risk factors versus markers of rheumatoid arthritis severity. Ann Rheum Dis 69: 1920-1925, 2010.

24. IL6R Genetics Consortium Emerging Risk Factors Collaboration, Sarwar N, Butterworth AS, Freitag DF, Gregson J, Willeit P, Gorman DN, Gao P, Saleheen D, Rendon A, et al: Interleukin-6 receptor pathways in coronary heart disease: A collaborative meta-analysis of 82 studies. Lancet 379: 1205-1213, 2012.
25. López-Mejías R, Genre F, García-Bermúdez M, Ubilla B, Castañeda S, Llorca J, González-Juanatey C, Corrales A, Miranda-Filloy JA, Pina T, et al: Lack of association between ABO, PPAP2B, ADAMST7, PIK3CG, and EDNRA and carotid intima-media thickness, carotid plaques and cardiovascular disease in patients with rheumatoid arthritis. Mediators Inflamm 756279, 2014.

26. Saag KG, Teng GG, Patkar NM, Anuntiyo J, Finney C, Curtis JR, Paulus HE, Mudano A, Pisu M, Elkins-Melton M, et al; American College of Rheumatology. American College of Rheumatology 2008 recommendations for the use of nonbiologic and biologic disease-modifying antirheumatic drugs in rheumatoid arthritis. Arthritis Rheum 59: 762-784, 2008.

27. van Halm VP, Peters MJ, Voskuyl AE, Boers M, Lems WF, Visser M, Stehouwer CD, Spijkerman AM, Dekker JM, Nijpels G, et al: Rheumatoid arthritis versus diabetes as a risk factor for cardiovascular disease: A cross-sectional study, the CARRE Investigation. Ann Rheum Dis 68: 1395-1400, 2009.

28. Quyyumi AA: Inflammed joints and stiff arteries: Is rheumatoid arthritis a cardiovascular risk factor? Circulation 114: 1137-1139, 2006.

29. López-Mejías R, Genre F, García-Bermúdez M, Corrales A, González-Juanatey C, Llorca J, José A Miranda-Filloy JA Rueda-Gotor J, Blanco R, Castañeda S, Martín J and González-Gay MA. The ZC3HC1 rs11556924 polymorphism is associated with increased carotid intima-media thickness in patients with rheumatoid arthritis. Arthritis Res Ther 15: R152, 2013.

30. Boyer JF, Gourraud PA, Cantagrel A, Davignon JL and Constantin A. Traditional cardiovascular risk factors in rheumatoid arthritis: A meta-analysis. Joint Bone Spine 78: 179-183, 2011.

31. Listing J, Strangfeld A, Kekow J, Schneider M, Kapelle A, Wassenberg S and Zink A. Does tumor necrosis factor alpha inhibition promote or prevent heart failure in patients with rheumatoid arthritis? Arthritis Rheum 58: 667-677, 2008.

32. Barnabe C, Martin BJ and Ghali WA. Systematic review and meta-analysis: Anti-tumor necrosis factor $\alpha$ therapy and cardiovascular events in rheumatoid arthritis. Arthritis Care Res (Hoboken) 63: 522-529, 2011

33. Van Siul AM, Van Den Hurk K, Peters MJ, Van Halm VP, Nijpels G, Stehouwer CD, Smulders YV, Voskuyl AE, Dekker JM and Nurmohamed MT: Different type of carotid arterial wall remodeling in rheumatoid athritis compared with healthy subjects: A case-control study. J Rheumatol 39: 2261-2266, 2012.

34. Del Rincón I, Williams K, Stern MP, Freeman GL, O'Leary DH and Escalante A: Association between carotid atherosclerosis and markers of inflammation in rheumatoid arthritis patients and healthy subjects. Arthritis Rheum 48: 1833-1840, 2003.

35. Irace C, Mancuso G, Fiaschi E, Madia A, Sesti G and Gnasso A. Effect of anti TNFalpha therapy on arterial diameter and wall shear stress and HDL cholesterol. Atherosclerosis 177: 113-118, 2004.

36. Schott LL, Cunhingnam A, Wildman RP, Kuller LH, Sutton-Tyrrel K and Wasko MC: Do carotid artery diameters manifest early evidence of atherosclerosis in women with rheumatoid arthritis? J Womens Health (Larchmt) 18: 21-29, 2009.

37. Roman MJ, Moeller E, Davis A, Paget SA, Crow MK, Lockshin MD, Sammaritano L, Devereux RB, Schwartz JE, Levine DM, et al: Preclinical carotid atherosclerosis in patients with rheumatoid arthritis. Ann Intern Med 144: 249-256, 2006. 